\title{
Heuristics: Tools for an Uncertain World
}

\author{
HANSJÖRG NETH and GERD GIGERENZER
}

\begin{abstract}
We distinguish between situations of risk, where all options, consequences, and probabilities are known, and situations of uncertainty, where they are not. Probability theory and statistics are the best tools for deciding under risk but not under uncertainty, which characterizes most relevant problems that humans have to solve. Uncertainty requires simple heuristics that are robust rather than optimal. We propose to think of the mind as an adaptive toolbox and introduce the descriptive study of heuristics, their building blocks, and the core capacities they exploit. The question of which heuristic to select for which class of problems is the topic of the normative study of ecological rationality. We discuss earlier views on the nature of heuristics that maintained that heuristics are always less accurate because they ignore information and demand less effort. Contrary to this accuracy-effort trade-off view, heuristics can lead to more accurate inferences-under uncertainty-than strategies that use more information and computation. The study of heuristics opens up a new perspective on the nature of both cognition and rationality. In a world of uncertainty, Homo sapiens might well be called Homo heuristicus.
\end{abstract}

\section{INTRODUCTION}

I suppose it is tempting, if the only tool you have is a hammer, to treat everything as if it were a nail.

Abraham H. Maslow (1966, p. 15f.)

\section{Heuristics are the answer to Simon's question:}

How do human beings reason when the conditions for rationality postulated by the model of neoclassical economics are not met? (Simon, 1989, p. 377)

Both Simon's question and our answer to it seem deceptively simple. Simon argues against the backdrop of a historic tradition that views the maximization of some notion of utility, the prescriptions of probability theory, or logical

Emerging Trends in the Social and Behavioral Sciences. Edited by Robert Scott and Stephan Kosslyn.

(C) 2015 John Wiley \& Sons, Inc. ISBN 978-1-118-90077-2. 
consistency as the hallmarks of human rationality. Ever since Fermat and Pascal's development of probability theory, Bayes' prescription of how to integrate novel and known information, and Laplace's proposal that probability theory was "basically just common sense reduced to calculus" (1814/1951, p. 196), probability theory has been seen by many as the exclusive criterion for rational behavior.

An alternative notion of rationality takes into consideration the ecological nature of human cognition, and argues that instead of one mighty hammer, we have many adaptive tools at our disposal and routinely rely on these heuristics. However, heuristics have often been equated with systematic biases. To unlock the positive potential of heuristics, it is necessary to acknowledge that it can be misguided to capture or combat real-world complexity with similarly complicated methods. Instead, the irreducible uncertainty of everyday environments often calls for simple solutions.

In this essay, we assert that people routinely rely on heuristics-not because they are irrational, but because they have to make decisions under uncertainty, where risk is not calculable. In these situations, they indeed should rely on heuristics, provided they do so in an ecologically rational way. To make this case, we begin by exploring different realms of rationality and illuminating Simon's notions of bounded rationality and satisficing in response to his question (section titled "Three Realms of Rationality"). To provide the necessary background to our answer, we then explicate the nature of heuristics (section titled "The Nature of Heuristics: Trade-offs, Biases, or Adaptive Tools?"). In the subsequent section, we introduce the descriptive study of heuristics, the study of the so-called adaptive toolbox (section titled "The Scientific Study of Heuristics"). Following that, we extend Simon's descriptive question to a normative one: Can we describe the structure of environments in which a given heuristic works or fails, in comparison with some other strategies? This analysis of the match between heuristics and environments is called the study of a heuristic's ecological rationality (section titled "The Normative Study of Ecological Rationality"). Finally, we end with the study of intuitive design, that is, designing heuristic tools for improving expert decisions "in the wild" (section titled "Intuitive Design: Decision Making in the Wild").

\section{THREE REALMS OF RATIONALITY}

In Hans Christian Andersen's tale The Emperor's New Clothes, the emperor falls prey to two tricksters who pretend to weave the most exquisite fabrics. Because these are universally believed to be invisible to anyone excessively stupid or unfit for their position, neither the emperor nor his ministers dare to disclose that they cannot see anything. Only when the emperor publicly 
Table 1

Three Realms of Rationality: Certainty, Risk, and Uncertainty

\begin{tabular}{|c|c|c|c|c|}
\hline Realm & $\begin{array}{l}\text { Type of } \\
\text { Problem }\end{array}$ & $\begin{array}{l}\text { Type of } \\
\text { Inference }\end{array}$ & $\begin{array}{l}\text { Appropriate } \\
\text { Tool }\end{array}$ & $\begin{array}{l}\text { People } \\
\text { Are ... }\end{array}$ \\
\hline Certainty & $\begin{array}{l}\text { All options and } \\
\text { consequences are known } \\
\text { for certain (known knowns) }\end{array}$ & $\begin{array}{l}\text { Deductive } \\
\text { inference }\end{array}$ & Logic & $\begin{array}{l}\text { Intuitive } \\
\text { logicians }\end{array}$ \\
\hline Risk & $\begin{array}{l}\text { All options and } \\
\text { consequences are known, } \\
\text { and their probabilities can } \\
\text { be reliably estimated } \\
\text { (known unknowns) }\end{array}$ & $\begin{array}{l}\text { Inductive } \\
\text { inference }\end{array}$ & $\begin{array}{l}\text { Probability } \\
\text { theory, } \\
\text { statistics }\end{array}$ & $\begin{array}{l}\text { Intuitive } \\
\text { statisticians }\end{array}$ \\
\hline Uncertainty & $\begin{array}{l}\text { III-posed or ill-defined } \\
\text { problems (unknown } \\
\text { unknowns) }\end{array}$ & $\begin{array}{l}\text { Heuristic } \\
\text { inference }\end{array}$ & $\begin{array}{l}\text { Heuristics, } \\
\text { ecological } \\
\text { rationality }\end{array}$ & $\begin{array}{l}\text { Homo } \\
\text { heuristicus }\end{array}$ \\
\hline
\end{tabular}

parades his nonexistent clothes does a small child call the hoax by crying out: "But the emperor has nothing on!"

When considering the question of how rational decisions should be made, part of the intellectual history of Western thought has succumbed to an analogous collective illusion-the illusion that formal logic and probability theory are sufficient for solving all relevant problems. However, applications of probability theory to unstable situations with high uncertainty have repeatedly failed. Examples are value-at-risk computations by large banks, which have missed every crisis and prevented none, and the end-of-year predictions of the euro-dollar exchange rates, which are notoriously inaccurate (Gigerenzer, 2014). The emerging science of heuristics assumes the role of the small child in Andersen's tale and aims to promote simple rules of thumb as an alternative route to rational behavior.

To understand this point, we need to carve up the landscape of rationality into three realms that are characterized by the type of information available to the organism whose rationality is being examined (see Table 1). When all necessary information to solve a given problem, that is, all options and all consequences, are known for certain, the problem is of the type "known knowns," and belongs to the realm of certainty. In a certain world, theories of logic model how to draw conclusions from premises. Although it is tempting to view logic as providing the "laws of thought," we should keep in mind that deductive inference is utterly conservative, and that certainty is rare. By explicating only information that is already contained in the premises, it never allows inferences to be generalized or drawn beyond the realm of known instances. 
Drawing inductive inferences involves risk, a second realm of rationality that is characterized by probability theory and various theories of statistical inference. In a risky world, it is assumed that all available options and consequences are known and that the probability distribution is also known or can be reliably estimated. These problems are known as "known unknowns," and the proper tool for solving them is statistical inference, to be made on the normative basis of probability theory.

Beyond the realms of certainty and risk exists a third realm in which not all options, consequences, or probabilities are/can be known: the realm of uncertainty. These are the kinds of problems to which Simon's question refers. In this world of "unknown unknowns," finding the best solutions by means of statistical optimization techniques is, by definition, no longer feasible. Instead, heuristics can be helpful to find good solutions. In his classic distinction between risk and uncertainty, Frank Knight emphasized that "a measurable uncertainty, or 'risk' proper ( ... ) is so far different from an unmeasurable one that it is not in effect an uncertainty at all." (Knight, 1921, p. 20). When laying out the Foundations of Statistics, Savage (1954) made it very clear that probability theory pertained only to predictable scenarios without surprises - even planning a picnic is out of this realm, according to Savage, because unexpected things may happen.

The distinction between the three realms illustrates why the theories of logic and probability theory can rule supremely within their respective realms but are overextended as universal standards of rationality. Similarly, Simon's question does not challenge the model of neoclassical economics where it is applicable, but instead asks how human beings behave beyond its reach, such as when probability distributions cannot be estimated because some options or consequences are unknown. In his search for an answer, Simon coined the term bounded rationality and proposed that humans use heuristics such as satisficing (Simon, 1955): Rather than attempting to find an optimal solution by searching through all alternatives and incorporating all available information, individuals can set themselves an aspiration level, sequentially inspect options, and choose the first one that meets or exceeds this level. Satisficing is an example of a heuristic decision strategy that works well "without ever making probability calculations" (Simon, 1955, p. 118).

But because satisficing provides no guarantee for finding the best solution, it seemed to many as if Simon merely replaced the ideal of optimization on the basis of extensive data collection and deliberation with the more modest goal of finding acceptable solutions with reasonable amounts of time and effort. This juxtaposition of decision quality and effort contributed to the view that heuristics inevitably involve trade-offs (e.g., between accuracy and speed), which we will discuss in the next section. Note, however, that Simon 
did not embrace heuristics as inferior alternatives to optimization but as our only viable option in a fundamentally uncertain world.

\section{THE NATURE OF HEURISTICS: TRADE-OFFS, BIASES, OR ADAPTIVE TOOLS?}

\section{Strategies for Discovery, Search, and Effort Reduction}

The notion of heuristics has undergone dramatic conceptual changes. Based on the Greek term for "serving to find out or discover," heuristics feature prominently in a variety of sciences and have played the roles of both villain and hero in accounts of human rationality (see Groner, Groner, \& Bischof, 1983). In physics, Albert Einstein presented his Nobel prize-winning ideas on the emission of light in 1905 as "a heuristic point of view" to indicate that his proposal was valuable but incomplete (Holton, 1988, pp. 360-361). Gestalt psychologists presented heuristic principles such as "looking around" as useful solution strategies (Wertheimer, 1923/1938), and mathematicians identified heuristics as essential methods for discovering mathematical proofs (Pólya, 1945). This inspired early researchers on human problem-solving to apply the notion of heuristic search to systematic methods of guiding and constraining mental navigation through large problem spaces (Newell \& Simon, 1972). According to the portrayal of people as adaptive decision-makers (Payne, Bettman, \& Johnson, 1993), people constantly negotiate trade-offs with their decision environments and can choose to sacrifice accuracy to gain efficiency or reduce effort.

\section{From Vague Labels to Formal Models}

This mix of positive and negative connotations surrounding the use of heuristics has led to two distinct interpretations in psychology. Within the framework of heuristics and biases (Tversky \& Kahneman, 1974), heuristics are interpreted as suboptimal shortcuts that inevitably lead to systematic errors and cognitive illusions. The problem with the "representativeness heuristic" (Kahneman \& Tversky, 1972) and similar vague notions was that these were not formally defined and thus could be used to explain almost everything after the fact, even $A$ and non- $A$, that is, a behavior as well as the opposite behavior (Ayton \& Fisher, 2004). Consider the gambler's fallacy: After a series of $n$ reds on the roulette table, the expectation of another red decreases. This fallacy was attributed to people's reliance on the representativeness heuristic because "the occurrence of black will result in a more representative sequence than the occurrence of an additional red" (Tversky \& Kahneman, 1974, p. 1125). Next, consider the hot-hand fallacy, which is the opposite belief: After a basketball player scores a series of $n$ hits, 
the expectation of another hit increases. This belief was equally attributed to representativeness because "even short random sequences are thought to be highly representative of their generating process" (Gilovich, Vallone, \& Tversky, 1985, p. 295). No scientific model should be able to explain both a phenomenon and its contrary. But a vague label can do this by changing its meaning.

Despite general acknowledgments that heuristics are "quite useful" (Tversky \& Kahneman, 1974, p. 1124) and "highly economical and usually effective" (p. 1131), those benefits are typically qualified by emphasizing that heuristics "lead to severe and systematic errors" (p. 1124). Kahneman (2003, p. 1449) made it perfectly clear that he views heuristics as sources of systematic deviations from the normative ideal of rationality:

“Our research attempted to obtain a map of bounded rationality, by exploring the systematic biases that separate the beliefs that people have and the choices they make from the optimal beliefs and choices assumed in rational-agent models."

By contrast, we advocate a brighter view of heuristics and pursue a different research agenda based on formal models of heuristics. Within the framework of the fast-and-frugal heuristics program (Gigerenzer, Todd, \& the ABC Research Group, 1999; Gigerenzer \& Gaissmaier, 2011; Gigerenzer, Hertwig, \& Pachur, 2011), heuristics are seen as adaptive tools that allow people to make accurate, efficient, and robust decisions under uncertainty. Rather than focusing on psychological follies and fallacies or compiling catalogs of human deviations from rational norms, we assume that heuristics are routinely relied on and often for good reasons, and aim to discover, analyze, and develop their positive potential. In studying when and why people use heuristics, we adopt the following definition:

Definition: Heuristics are adaptive tools that ignore information to make fast and frugal decisions that are accurate and robust under conditions of uncertainty.

Several aspects of this definition are noteworthy. ${ }^{1}$ First, describing heuristics as tools emphasizes their methodological nature and status as means to make decisions, rather than as ends in themselves. Yet, in some cases, understanding the heuristic can help to clarify what exactly the end is

1. Two aspects frequently mentioned in other accounts (e.g., Evans, 2008, Kahneman 2003) are notably absent from our definition, namely, that heuristics (i) are used "unconsciously" and (ii) reflect the workings of some "System 1." As we believe that any heuristic can be applied both consciously or unconsciously and prefer testable process models of heuristics to opaque descriptions that tend to exhaust themselves in long lists of dichotomies, we prefer to abstain from such characterizations (see Kruglanski \& Gigerenzer, 2011 for a critical review). 
(Gigerenzer \& Selten, 2001). In psychological studies of human cognition, making decisions typically involves mental strategies. But our notion of heuristics also includes algorithmic procedures for expert systems in applied domains (e.g., in financial, legal, or medical contexts; see section titled "Intuitive Design: Decision Making in the Wild"). In either case, we consider it essential that heuristics are formulated as precise process models that yield testable predictions. Second, the qualifier adaptive implies that a successful use of heuristics depends on experience and the degree of fit between decision strategies and environmental structures (see below). Third, our definition agrees with previous accounts that a primary motivation for using heuristics is making fast and frugal decisions but differs in emphasizing that this increase in efficiency does not necessarily entail a decrease in effectiveness or decision quality. Whether the benefits of heuristics come at a cost is not an a priori issue or matter of opinion, but an empirical question. In fact, one of the surprising discoveries is that heuristics can avoid the trade-off between speed and accuracy and often yield more accurate and robust results than more effortful methods. Finally, the natural habitat of heuristics is the realm of uncertainty. As we have argued in the previous section, this is hardly much of a constraint, as this realm comprises the vast majority of situations under which "the conditions for rationality postulated by the model of neoclassical economics are not met" (Simon, 1989, p. 377).

In short, existing perspectives on heuristics paint a deeply ambivalent picture of heuristics by portraying them as valuable strategies involving trade-offs, as vices leading to systematic biases, or as adaptive tools allowing for accurate and robust decisions in a fast and frugal manner. To disentangle this conceptual confusion, the scientific study of heuristics needs to examine both descriptive and normative research questions. We will ask and answer these questions in the following sections.

\section{THE EMERGING SCIENCE OF HEURISTICS}

The descriptive question when studying heuristics is:

Which heuristics do people use?

The result of this investigation yields an arsenal of heuristics that are organized in an adaptive toolbox. Unable to discuss all the heuristics that it contains (see Table 2 for an illustrative but incomplete list), we provide some examples before discussing their general properties in more detail. 


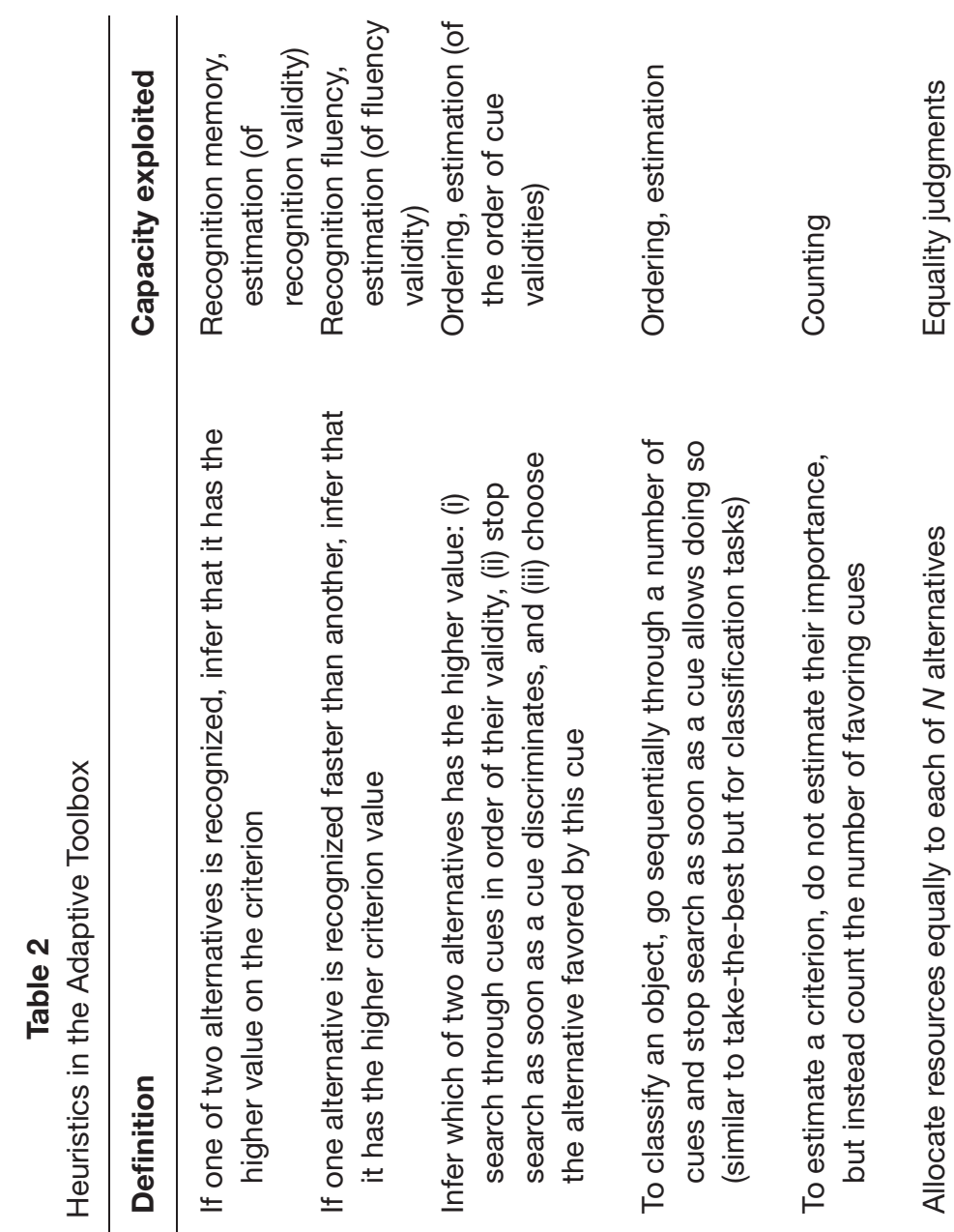

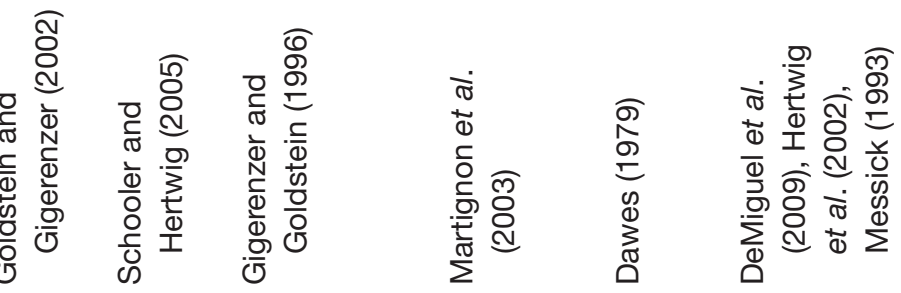

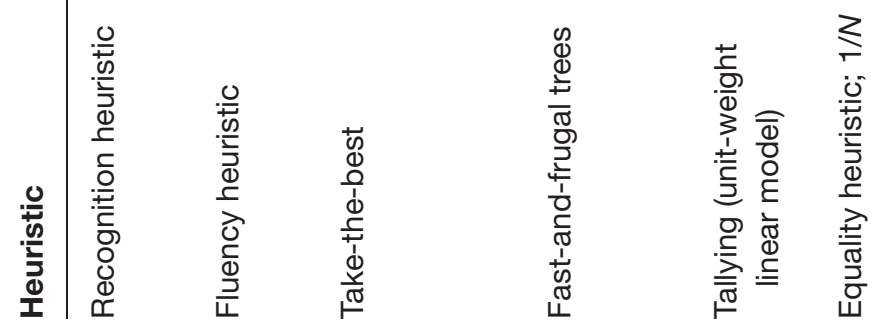



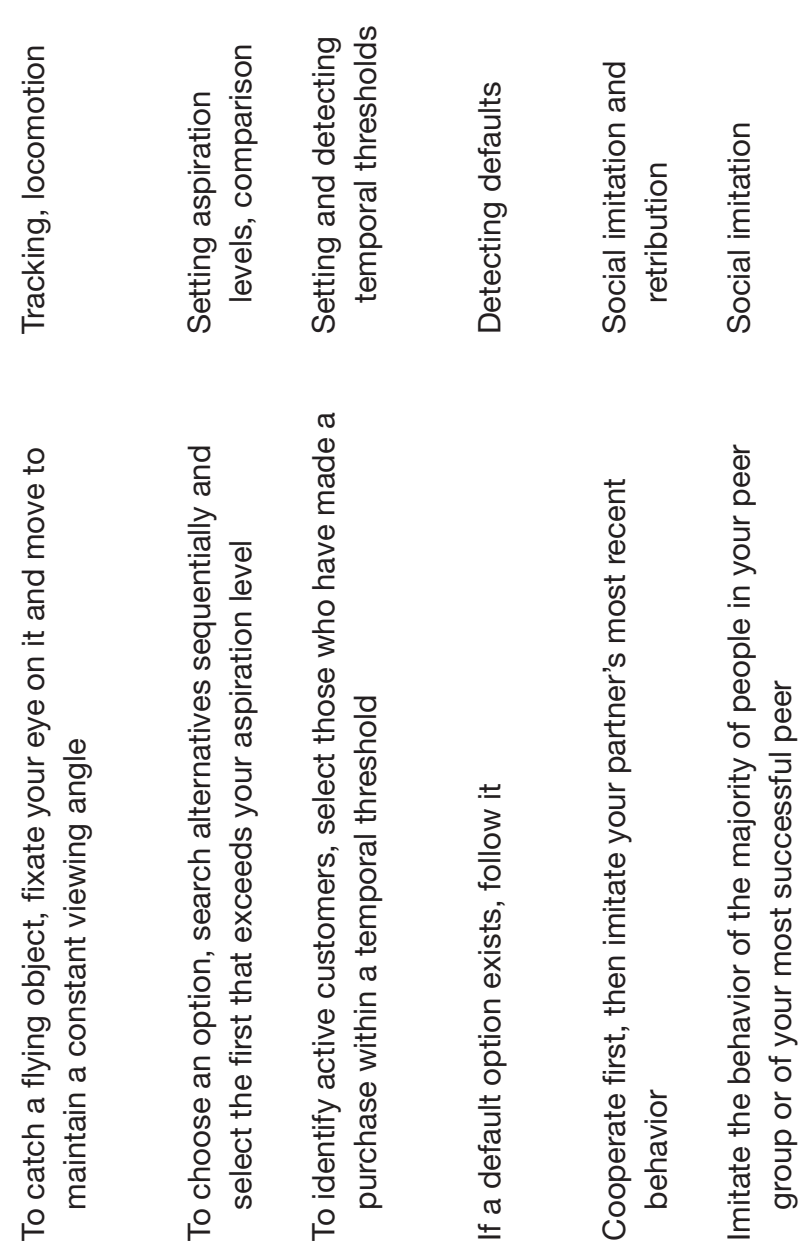

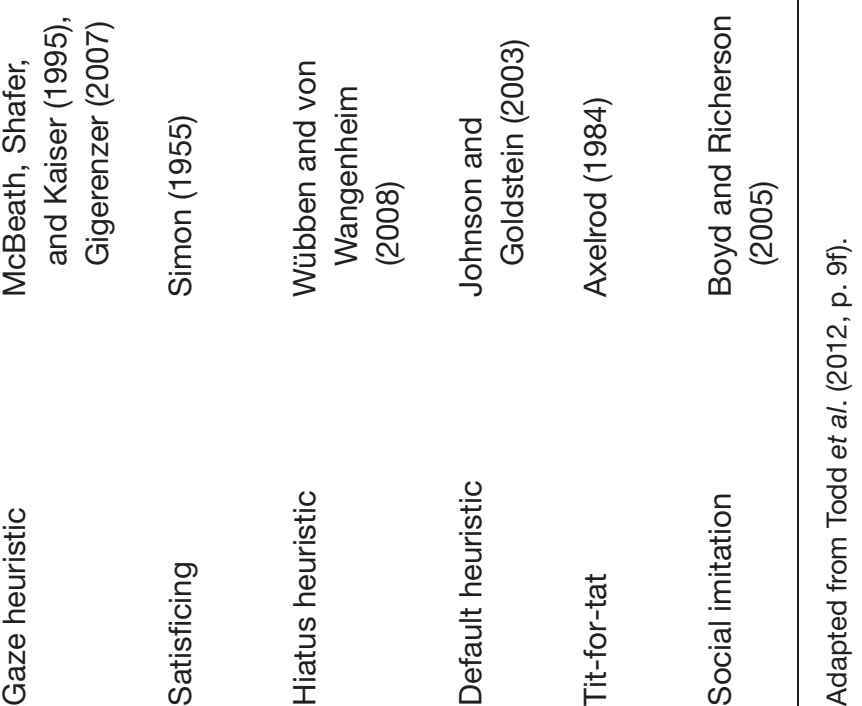


Recognition Heuristic

How do people infer which of two alternatives is bigger or better according to some criterion? For instance, which of the following two cities has more inhabitants:

\section{Detroit or Milwaukee?}

About $60 \%$ of a sample of people living in the United States correctly answered this question with "Detroit." Surprisingly, the proportion of British or German citizens correctly answering the same question was 80-90\% (Gigerenzer \& Goldstein, 2011). Does this mean that Europeans know more about US cities than US citizens do? No-in fact, the Europeans benefit from knowing less. Because many of them recognize the name of Detroit but have not heard of Milwaukee, they can apply the recognition heuristic (RH; Goldstein \& Gigerenzer, 2002):

If only one of two alternatives is recognized, infer that it has the higher value with respect to the criterion.

The RH makes the bold prediction of a less-is-more effect: If the recognition validity (defined as the proportion of correct inferences when only one alternative is recognized) exceeds the knowledge validity (defined as the proportion of correct inferences when both alternatives are recognized), an increase in the number of recognized alternatives beyond some level causes a decrease in accuracy. And, although the RH is so simple that it may seem naïve, it has been successfully used to predict consumer choices, election results, the winners of the Wimbledon tennis matches, and the performance of investment portfolios (for overviews, see Marewski, Pohl, \& Vitouch, 2010, 2011).

\section{$1 / N$ Heuristic}

How should we allocate available resources to assets, for example, when investing money? According to traditional finance theory, maximizing profit implies a trade-off between risk and return. The Nobel-prize winning mean-variance model of Markowitz (1952) solved this problem by maximizing profit for a given level of variance (risk). An alternative strategy is the simple $1 / N$ heuristic, which appears as early as in the Talmud:

Allocate all resources equally to each of $N$ alternative assets.

Benartzi and Thaler (2001) observed that investors tend to use this "naïve diversification" method in their contributions to retirement savings plans and concluded that this may incur substantial costs. But, when DeMiguel, 
Garlappi, and Uppal (2009) compared the performance of the Markowitz model and its modern variants with the $1 / N$ heuristic, the mathematically sophisticated strategies failed to outperform the seemingly naïve heuristic. ${ }^{2}$

\section{The Scientific Study of Heuristics}

The systematic study of heuristics requires precise models of the cognitive processes and their building blocks, and an analysis of the cognitive or perceptuo-motor core capacities that heuristics exploit. Heuristics typically recruit and rely on evolved and learned core capacities (such as recognition memory, which is known to precede conscious recollection; Ratcliff \& McKoon, 1989), and exploit regularities in the external environment (e.g., that the recognition of city names tends to be positively correlated with population size). Although no complete taxonomy exists, heuristics can be sorted into categories such as recognition-based rules $(\mathrm{RH}$, fluency heuristic), heuristics relying on one good reason (take-the-best, gaze heuristic, hiatus heuristic), and trade-off heuristics (tallying, 1/N; see Gigerenzer \& Gaissmaier, 2011, for additional examples). Note that heuristics are not isolated from each other, but share knowledge structures and frequently contain three common building blocks:

Search rules specify what information is considered and in which order or direction information search proceeds.

Stopping rules specify when the search for information is terminated.

Decision rules specify how the final decision is reached.

By combining building blocks, heuristics can be adopted and adjusted to form new heuristics. For instance, the $1 / N$ heuristic for financial allocation decisions is a specialized instance of a more general equality rule (Messick, 1993) that also appears to govern parental investments (Hertwig, Davis, \& Sulloway, 2002). Similarly, the so-called hiatus heuristic (Wübben \& von Wangenheim, 2008), which companies use to predict which customers will purchase in the future, is related to optimal stopping rules considered in animal foraging theory (Green, 1984) and research on humans when switching between multiple tasks (Payne, Duggan, \& Neth, 2007). Additionally, combining building blocks or heuristics can yield new heuristics, such as when merging satisficing with tallying to create a new heuristic that selects an alternative as soon as a certain number of criteria are met. These transformations show that the adaptive toolbox does not consist of a fixed

2. Markowitz himself used $1 / N$ instead of his own model of portfolio optimization (Benartzi \& Thaler, 2001, p. 80). 
set of heuristics but is a flexible and fluid collection that can be shaped by the demands of adaptive agents, the current task, and task environments.

Crucially, our stipulation that heuristics must be specified as formal process models (or explicit algorithms) turns the study of the adaptive toolbox into a productive research program that not only yields new questions-including "How do we select heuristics?" (Rieskamp \& Otto, 2006) and "For which cognitive and environmental niches are they most suited?" (Marewski \& Schooler, 2011)—but also makes their performance measurable by yielding testable predictions. This enables us to address the question of heuristic performance as an empirical issue rather than accepting their alleged inferiority as a predetermined conclusion. For a given heuristic, this task involves specifying the conditions under which it works or fails as measured by some criterion of performance, such as accuracy.

\section{THE NORMATIVE STUDY OF ECOLOGICAL RATIONALITY}

With the help of precise models of heuristics, Simon's descriptive question can be extended to a normative one:

When should people rely on heuristics rather than on more complex strategies?

Why Heuristics Work

To answer the normative question of heuristics, we crucially need to understand why heuristics work (e.g., Gigerenzer, 2008). The answers can be expressed in both ecological and statistical terms. Ecologically, identifying the conditions under which heuristics work well must consider the interplay between a particular strategy and the structure of its task environment. Heuristics generally tend to be successful if the conditions of ecological rationality are met, that is, if (i) a high degree of match exists between the heuristic and the structure of the task environment and (ii) the organism has the core capacities necessary for applying the heuristic (Todd, Gigerenzer, \& the ABC Research Group, 2012). Only when agents have particular capacities is using heuristics simple or effortless per se. For instance, aiming to construct a robot that applies the gaze heuristic (see Table 2) to intercept a flying object would demand specific core capacities that robots do not yet have, such as tracking moving objects against a noisy background.

The statistical answer to the normative question is based on the difference between fitting models to data and predicting future events on the basis of past observations. A more flexible model (e.g., with additional free parameters) will always provide an equal or better fit to existing data than 
a simpler model will (Gigerenzer \& Brighton, 2009, for examples). But, the main purpose of scientific models is not to explain post hoc, but to predict similar events in the future. ${ }^{3}$ Mathematically, the relevant characteristics of different types of models can be analyzed in terms of the bias-variance dilemma (Geman, Bienenstock, \& Doursat, 1992), which decomposes a model's expected prediction error into three parts:

$$
\text { prediction error }=(\text { bias })^{2}+\text { variance }+ \text { noise }
$$

In this sum, the bias term describes the average accuracy of an algorithm's predictions, the variance term describes the variation in a model's predictions given different samples, and the noise term contains unsystematic deviations, such as measurement error. Crucially, a more flexible model generally tends to exhibit both lower bias and higher variance. A model with high bias will tend to underfit the data (i.e., miss existing patterns), whereas a model with high variance will typically overfit them (i.e., "explain" even random noise). Consequentially, a successful model must balance bias and variance in order to achieve high predictive accuracy.

How can the bias-variance dilemma explain the success of heuristics such as $1 / N$ ? Markowitz's (1952) model assigns a weight to every available asset and needs to estimate all means and variances, as well as the covariance matrix. What makes the mean-variance model prone to error are these estimates, not the complexity of its calculations. By contrast, the $1 / \mathrm{N}$ heuristic completely ignores historic information and assigns a fixed weight of $1 / N$ to every asset. Thus, the Markowitz model is highly flexible and reduces bias at the expense of increased variance, whereas $1 / N$ is likely to exhibit a high bias but no variance. If a large amount of relevant data were available and the world of investment were stable, the Markowitz model would outperform $1 / N$. But the key is that we are dealing with uncertainty rather than with risk: Even with an abundance of financial data, the dynamics of financial markets are such that only a small proportion of the available data may actually be relevant to the current economic conditions. And, when relevant data are sparse, the variance term tends to dominate the bias term and thus increase the overall prediction error of complex models.

Taken together, these considerations allow us not only to provide an answer to the normative question (When should we rely on heuristics?), but also to disentangle the conceptual confusion about heuristics by explaining why older, nonadaptive notions of heuristics were unable to discover and comprehend their benefits. Heuristics work well when they are adapted to

3. Otherwise, the model "it was due to fate" would perfectly (and parsimoniously) "explain" everything. 
solving problems in uncertain environments. Situations with high levels of uncertainty, high degrees of complexity (e.g., a large number of options), and small amounts of relevant data tend to favor simple models over more flexible ones. When the primary concerns are predictive accuracy and an understanding of generative mechanisms - that is, success in uncertain environments, or designing scientific models-simple heuristics can outperform more flexible ones by yielding more robust results. In a world of risk, it is sensible to collect all data and integrate it according to the laws of probability theory. But in situations of uncertainty, where an optimal solution can no longer be calculated, heuristics are adaptive tools that make uncertainty manageable.

\section{Intuitive Design: Decision-Making in the Wild}

The descriptive study of the adaptive toolbox of individuals and institutions and the normative study of the conditions of ecological rationality have important consequences for the design of psychological theories. First, the study of the adaptive toolbox provides an alternative to the widespread understanding of human behavior in terms of internal traits, preferences, or attitudes: Behavior is a function of cognition and environment in tandem. This view has been applied to better understand moral behavior (Fleischhut \& Gigerenzer, 2013), the nature of intuition (Gigerenzer, 2007), legal decision-making (Dhami, 2003), and social behavior in general (Hertwig, Hoffrage, \& the ABC Research Group, 2013).

The answers to the descriptive and normative question have been used to improve experts' decision-making and decisions "in the wild" (Gigerenzer et al., 2011). In this program of intuitive design, the resulting decision systems are designed to fit the intuitive strategies people use. For instance, fast-and-frugal trees (Martignon, Vitouch, Takezawa, \& Forster, 2003, Table 2) have been designed for coronary care unit allocation (Green \& Mehr, 1997), for diagnosing depression (Jenny, Pachur, Lloyd Williams, Becker, \& Margraf, 2013), for reducing civilian casualties at military checkpoints (Keller, Czienskowski, \& Feufel, 2014), and for detecting vulnerable banks (Aikman et al., 2014; Neth, Meder, Kothiyal, \& Gigerenzer, 2014). In all this applied work, the design of heuristics can provide efficient tools in an uncertain world.

As mentioned in the beginning, optimization is not possible under uncertainty, but good decisions are. Heuristics are tools toward this end, which, as far as we know, humans have always relied on to solve adaptive problems. Moreover, given that humans, past and present, spend most of their time in the twilight of uncertainty, the nature of Homo sapiens might well be found in Homo heuristicus. 


\section{REFERENCES}

Aikman, D., Galesic, M., Gigerenzer, G., Kapadia, S., Katsikopoulos, K. V., Kothiyal, A., Murphy, E., \& Neumann, T. (2014). Taking uncertainty seriously: Simplicity versus complexity in financial regulation. Bank of England Financial Stability Paper, 28.

Axelrod, R. M. (1984). The evolution of cooperation. New York, NY: Basic Books.

Ayton, P., \& Fisher, I. (2004). The hot hand fallacy and the gambler's fallacy: Two faces of subjective randomness? Memory and Cognition, 32, 1369-1378.

Benartzi, S., \& Thaler, R. H. (2001). Naive diversification strategies in defined contribution saving plans. American Economic Review, 91(1), 79-98.

Boyd, R., \& Richerson, P. J. (2005). The origin and evolution of cultures. New York, NY: Oxford University Press.

Dawes, R. M. (1979). The robust beauty of improper linear models in decision making. American Psychologist, 34(7), 571-582.

DeMiguel, V., Garlappi, L., \& Uppal, R. (2009). Optimal versus naive diversification: How inefficient is the 1/N portfolio strategy? Review of Financial Studies, 22(5), 1915-1953.

Dhami, M. K. (2003). Psychological models of professional decision making. Psychological Science, 14(2), 175-180.

Evans, J. S. B. T. (2008). Dual-processing accounts of reasoning, judgment, and social cognition. Annual Review of Psychology, 59, 255-278.

Fleischhut, N., \& Gigerenzer, G. (2013). Can simple heuristics explain moral inconsistencies?. In R. Hertwig, U. Hoffrage \& the ABC Research Group, Simple heuristics in a social world (pp. 459-486). New York, NY: Oxford University Press.

Geman, S., Bienenstock, E., \& Doursat, R. (1992). Neural networks and the bias/ variance dilemma. Neural Computation, 4(1), 1-58.

Gigerenzer, G. (2007). Gut feelings: The intelligence of the unconscious. New York, NY: Penguin.

Gigerenzer, G. (2008). Rationality for mortals: Risk and rules of thumb. New York, NY: Oxford University Press.

Gigerenzer, G. (2014). Risk savoy: How to make good decisions. New York, NY: Allan Lane.

Gigerenzer, G., \& Brighton, H. (2009). Homo heuristicus: Why biased minds make better inferences. Topics in Cognitive Science, 1(1), 107-143.

Gigerenzer, G., \& Gaissmaier, W. (2011). Heuristic decision making. Annual Review of Psychology, 62(1), 451-482.

Gigerenzer, G., \& Goldstein, D. G. (1996). Reasoning the fast and frugal way: Models of bounded rationality. Psychological Review, 103, 650-669.

Gigerenzer, G., \& Goldstein, D. G. (2011). The recognition heuristic: A decade of research. Judgment and Decision Making, 6(1), 100-121.

Gigerenzer, G., Hertwig, R., \& Pachur, T. (Eds.) (2011). Heuristics: The foundations of adaptive behavior. New York, NY: Oxford University Press.

Gigerenzer, G., \& Selten, R. (2001). Rethinking rationality. In G. Gigerenzer \& R. Selten (Eds.), Bounded rationality: The adaptive toolbox (pp. 1-12). Cambridge, MA: MIT Press. 
Gigerenzer, G., Todd, P. M., \& the ABC Research Group (1999). Simple heuristics that make us smart. New York, NY: Oxford University Press.

Gilovich, T., Vallone, R., \& Tversky, A. (1985). The hot hand in basketball: On the misperception of random sequences. Cognitive Psychology, 17, 295-314.

Goldstein, D. G., \& Gigerenzer, G. (2002). Models of ecological rationality: The recognition heuristic. Psychological Review, 109(1), 75-90.

Green, R. F. (1984). Stopping rules for optimal foragers. The American Naturalist, 123(1), 30.

Green, L., \& Mehr, D. R. (1997). What alters physicians' decisions to admit to the coronary care unit? Journal of Family Practice, 45(3), 219-226.

Groner, R., Groner, M., \& Bischof, W. (1983). Approaches to heuristics: A historical review. In R. Groner, M. Groner \& W. Bischof (Eds.), Methods of heuristics (pp. 1-17). Hillsdale, NJ: Lawrence Erlbaum Associates.

Hertwig, R., Davis, J. N., \& Sulloway, F. J. (2002). Parental investment: How an equity motive can produce inequality. Psychological Bulletin, 128(5), 728-745.

Hertwig, R., Hoffrage, U., \& the ABC Research Group (2013). Simple heuristics in a social world. New York, NY: Oxford University Press.

Holton, G. J. (1988). Thematic origins of scientific thought: Kepler to Einstein (2nd ed.). Cambridge, MA: Harvard University Press.

Jenny, M. A., Pachur, T., Lloyd Williams, S., Becker, E., \& Margraf, J. (2013). Simple rules for detecting depression. Journal of Applied Research in Memory and Cognition, 2(3), 149-157.

Johnson, E. J., \& Goldstein, D. (2003). Do defaults save lives? Science, 302(5649), 1338-1339.

Kahneman, D. (2003). Maps of bounded rationality: Psychology for behavioral economics. American Economic Review, 93, 1499-1475.

Kahneman, D., \& Tversky, A. (1972). Subjective probability: A judgment of representativeness. Cognitive Psychology, 3(3), 430-454.

Keller, N., Czienskowski, U., \& Feufel, M. (2014). Tying up loose ends: A method for constructing and evaluating decision aids that meet blunt and sharp-end goals. Ergonomics, 1-13PMID: 24852324.

Knight, F. H. (1921). Risk, uncertainty and profit. Chicago, IL: University of Chicago Press.

Kruglanski, A. W., \& Gigerenzer, G. (2011). Intuitive and deliberate judgments are based on common principles. Psychological Review, 118(1), 97-109.

Marewski, J. N., Pohl, R. F., \& Vitouch, O. (2010). Recognition-based judgments and decisions: Introduction to the special issue (Vol. 1). Judgment and Decision Making, 5(4), 207-215.

Marewski, J. N., Pohl, R. F., \& Vitouch, O. (2011). Recognition-based judgments and decisions: Introduction to the special issue (Vol. 2). Judgment and Decision Making, 6(1), 1-6.

Marewski, J. N., \& Schooler, L. J. (2011). Cognitive niches: An ecological model of strategy selection. Psychological Review, 118(3), 393-437.

Markowitz, H. M. (1952). Portfolio selection. The Journal of Finance, 7, 77-91. 
Martignon, L., Vitouch, O., Takezawa, M., \& Forster, M. R. (2003). Naïve and yet enlightened: From natural frequencies to fast and frugal decision trees. In D. Hardman \& L. Macchi (Eds.), Thinking: Psychological perspectives on reasoning, judgment and decision making (pp. 189-211). Chichester, UK: Wiley.

Maslow, A. H. (1966). The psychology of science. New York, NY: Harper \& Row.

McBeath, M. K., Shaffer, D. M., \& Kaiser, M. K. (1995). How baseball outfielders determine where to run to catch fly balls. Science, 268(5210), 569-573.

Messick, D. M. (1993). Equality as a decision heuristic. In B. A. Mellers \& J. Baron (Eds.), Psychological perspectives on justice: Theory and applications (pp. 11-31). Cambridge, MA: Cambridge University Press.

Neth, H., Meder, B., Kothiyal, A., \& Gigerenzer, G. (2014). Homo heuristicus in the financial world: From risk management to managing uncertainty. Journal of Risk Management in Financial Institutions, 7(2), 134-144.

Newell, A., \& Simon, H. A. (1972). Human problem solving. Englewood Cliffs, NJ: Prentice Hall.

Payne, J. W., Bettman, J. R., \& Johnson, E. J. (1993). The adaptive decision maker. Cambridge, UK: Cambridge University Press.

Payne, S., Duggan, G., \& Neth, H. (2007). Discretionary task interleaving: Heuristics for time allocation in cognitive foraging. Journal of Experimental Psychology: General, 136(3), 370-380.

Pólya, G. (1945). How to solve it: A new aspect of mathematical method. Princeton, NJ: Princeton University Press.

Ratcliff, R., \& McKoon, G. (1989). Similarity information versus relational information: Differences in the time course of retrieval. Cognitive Psychology, 21(2), 139-155.

Rieskamp, J., \& Otto, P. E. (2006). SSL: A theory of how people learn to select strategies. Journal of experimental psychology: General, 135(2), 207-236.

Savage, L. J. (1954). The foundations of statistics (2nd ed.). New York, NY: Dover.

Schooler, L. J., \& Hertwig, R. (2005). How forgetting aids heuristic inference. Psychological Review, 112(3), 610-628.

Simon, H. A. (1955). A behavioral model of rational choice. The Quarterly Journal of Economics, 69(1), 99-118.

Simon, H. A. (1989). The scientist as problem solver. In K. Klahr \& D. Kotovsky (Eds.), Complex information processing: The impact of Herbert A. Simon (pp. 377-398). Hillsdale, NJ: Lawrence Erlbaum.

Todd, P. M., Gigerenzer, G., \& the ABC Research Group (2012). Ecological rationality: Intelligence in the world. New York, NY: Oxford University Press.

Tversky, A., \& Kahneman, D. (1974). Judgment under uncertainty: Heuristics and biases. Science, 185(4157), 1124-1131.

Wertheimer, M. (1923/1938). Untersuchungen zur Lehre von der Gestalt. (English excerpts: Laws of organization in perceptual forms). In W. Ellis (Ed.), A source book of Gestalt psychology (pp. 71-88). New York, NY: Hartcourt, Brace and Co.

Wübben, M., \& von Wangenheim, F. (2008). Instant customer base analysis: Managerial heuristics often 'get it right'. Journal of Marketing, 72(3), 82-93. 


\section{HANSJÖRG NETH SHORT BIOGRAPHY}

Hansjörg Neth is researcher in Social Psychology and Decision Sciences at the University of Konstanz, Germany, and adjunct researcher at the Center for Adaptive Behavior and Cognition (ABC) at the Max Planck Institute for Human Development, Berlin. His research focuses on the theoretical analysis of adaptive behavior, interactive cognition, and ecological rationality, as well as applied aspects of choice and heuristic decision-making under uncertainty (e.g., in financial contexts). He has served as acting chair of Cognition, Emotion, and Communication at the University of Freiburg, taught Cognitive and Decision Sciences at the University of Göttingen, and was research assistant professor in Cognitive Science at the Rensselaer Polytechnic Institute. He holds a PhD in psychology from Cardiff University, UK.

\section{GERD GIGERENZER SHORT BIOGRAPHY}

Gerd Gigerenzer is Director at the Max Planck Institute for Human Development and Director of the Harding Center for Risk Literacy in Berlin. He is former Professor of Psychology at the University of Chicago and John M. Olin Distinguished Visiting Professor, School of Law at the University of Virginia. He is also Member of the Berlin-Brandenburg Academy of Sciences and the German Academy of Sciences, and Batten Fellow at the Darden Business School, University of Virginia. Awards for his work include the AAAS Prize for the best article in the behavioral sciences, the Association of American Publishers Prize for the best book in the social and behavioral sciences, and the Communicator Award of the German Research Foundation. His award-winning popular books Calculated Risks, Gut Feelings, and Risk Savoy have been translated into 21 languages. 